\title{
Direito a acompanhante: tutela dos direitos sexuais e reprodutivos das parturientes
}

\author{
durante a pandemia da Covid-19
}

\section{Right to companion: protection of the sexual and reproductive rights of parturients during the pandemic of Covid-19}

\author{
Luciana Santos Silva ${ }^{1}$ \\ Lidiane Lima Silva ${ }^{2}$ \\ Arantxa Honorina Leão Batista dos Prazeres ${ }^{3}$
}

\begin{abstract}
Resumo: O presente trabalho tem como objetivo discorrer sobre a garantia do direito a acompanhante no pré-parto, parto e pós-parto para a mulher parturiente ou em processo de abortamento durante a pandemia da Covid-19, em face da Nota Técnica no 69, emitida em 02 de junho de 2020 pela Secretaria de Saúde do Estado da Bahia, que orienta as Unidades de Saúde e Secretarias Municipais de Saúde a suprimir tal direito como medida de controle do processo epidêmico da Covid-19 no estado da Bahia.
\end{abstract}

Palavras-chave: Acompanhante. Covid-19. Direitos Humanos. Mulher. Parturiente.

Abstract: This paper aims to discuss the guarantee of the right to a companion in prepartum, childbirth and postpartum for the parturient woman or in the process of aborti on during the Covid-19 pandemic, with respect to Technical Note 69, issued on June 2, 2020 by the Health Department of the State of Bahia, which guides the Health Units and Municipal Health Departments to suppress this right a same sure of control of the epidemic process of Covid-19 in the state of Bahia.

Keywords: Birth. Companion. Covid-19. Human Rights. Woman.

\section{Introdução}

A gravidez, o aborto, o parto e puerpério, enquanto eventos sociais, biológicos e fisiológicos estreitamente relacionados aos direitos reprodutivos das mulheres, precisam ser tratados sempre sob a ótica da humanização e das questões de gênero. Humanizar requer diversos quesitos, tais como garantir a assistência médica qualificada, dispor de um ambiente adequado e, principalmente, no que tange aos direitos femininos, permitir o protagonismo da mulher, respeitando suas escolhas e necessidades, levando em conta as especificidades médicas e o consentimento esclarecido.

\footnotetext{
${ }^{1}$ Doutora pela PUC/SP, docente do curso de Direito da Universidade Estadual do Sudoeste da Bahia. Coordenadora da Clínica de Direitos Humanos da Universidade Estadual do Sudoeste da Bahia. Líder do Grupo de pesquisa Direitos Humanos, Democracia e Discurso Contra-Hegemônico e advogada. E-mail: luciana.silva@uesb.edu.br.

${ }^{2}$ Graduanda em Direito. Integrante da Clínica de Direitos Humanos da Universidade Estadual do Sudoeste da Bahia, integrante do Grupo de pesquisa Direitos Humanos, Democracia e Discurso Contra-Hegemônico. Vice-presidente da Comissão Administrativa da Revista Científica do Curso de Direito - RCCD. E-mail: limasilvalidiane@gmail.com. ${ }^{3}$ Graduanda em Direito. Integrante da Clínica de Direitos Humanos da Universidade Estadual do Sudoeste da Bahia e do Grupo de pesquisa Direitos Humanos, Democracia e Discurso Contra-Hegemônico. E-mail: arantxahlbp@gmail.com.
} 
O direito a acompanhante surge, então, como mecanismo para humanizar o parto, uma vez que a mulher passa a dispor da opção de ter ao seu lado alguém que lhe possa transmitir confiança e que, ao mesmo tempo, tem a possibilidade de fiscalizar todo o procedimento de forma atenta. Tal direito, disposto no artigo 19-J da Lei no 8.080/1990 (Lei do SUS), foi estabelecido pela Lei no 11.108 , de 07 de abril de 2005, normatizando a garantia da parturiente ao direito à presença de acompanhante durante o trabalho de parto, parto e pós-parto imediato no Sistema Único de Saúde (SUS), da rede própria ou conveniada. Importante destacar que essas instituições possuem a obrigação de garantir tal direito.

A literatura médica indica que o acompanhante escolhido pela gestante gera inúmeros benefícios para a mulher, tais como segurança, conforto e cuidado. As estudiosas Longo, Andraus e Barbosa ressaltam que o fato de contar com um acompanhante durante o parto pode refletir positivamente no comportamento da parturiente durante a parturição, uma vez que essa presença traz consigo significados diversos. Tal participação configura uma parte do imaginário da gestante quando esta pensa no seu parto. Segundo as autoras "nele é depositada pela parturiente a segurança de ter alguém próximo e confiável, assim como é à equipe de profissionais que ela atribui a tarefa do atendimento do manejo do parto.”(LONGO, ANDRAUS, BARBOSA, 2010. p.388).

A presença de acompanhante durante o trabalho de parto, parto e pós-parto consolidou-se como direito a partir do reconhecimento científico dos seus benefícios e, sobretudo, devido à atuação dos movimentos feministas. No plano internacional, a Convenção sobre a Eliminação de Todas as Formas de Discriminação contra as Mulheres, a Declaração e Programa de Ação de Viena e a Convenção Relativa ao Amparo ao Parto determinam a presença de acompanhante de livre escolha da mulher como forma de humanização do parto.

Insta delimitar que o direito a acompanhante, nos moldes da lei brasileira (art.19-J da Lei $n^{\circ}$ 8.080/1990), em concordância com a Recomendação da OMS e com a Convenção Americana de Direitos Humanos, abrange as gestantes e também as mulheres que sofreram aborto. De acordo com a legislação nacional, ambas possuem o direito de ingressar nos hospitais com o acompanhante a sua escolha.

O presente artigo problematiza os contornos do direito a acompanhante durante o trabalho de parto, parto e pós-parto, no período da pandemia da Covid-19, com recorte no estado da Bahia. Assim, a construção do campo de pesquisa ocorreu mediante levantamento de documentos oficiais do governo do estado da Bahia, da Organização Mundial de Saúde e do Ministério da Saúde sobre o tema, estudo bibliográfico, mapeamento de notícias sobre ações e decisões judiciais que garantem o direito de acompanhante durante o trabalho de parto, parto e pós-parto durante o período da pandemia da Covid19, bem como análise da legislação pertinente.

Os documentos consultados e as decisões judiciais não constarão nas referências bibliográficas, pois constituem o campo de pesquisa a ser analisado e não suporte para sua interpretação. A busca de documentos oficiais e das notícias sobre judicialização e em favor do direito pesquisado ocorreu por meio 
da ferramenta de pesquisa do Google (https://www.google.com.br/) e das palavras chaves: "direito acompanbante gestante pandemia; direito acompanbante gestante coronavirus e direito acompanbante gestante liminar". As discussões decorrentes desse estudo são apresentadas nos tópicos seguintes sopesando o direito de acompanhamento em tempo de pandemia.

\section{Reflexos da Covid-19 no direito ao acompanhante, previsto na Lei $\mathrm{n}^{\circ}$ 8.080/1990: ilegalidade da restrição absoluta}

$\mathrm{Na}$ primeira quinzena de março deste ano, 2020, a Covid-19 foi considerada pela Organização Mundial da Saúde (OMS) uma pandemia, sendo amplamente divulgado que se trata de uma doença infecciosa causada pelo novo Coronavírus, SARS-CoV-2.

Assim, devido à sua gravidade, a Covid-19 tem gerado muitos debates na comunidade científica e nas esferas de decisões políticas. Apesar da falta de consenso em relação à forma com a qual se deve enfrentar essa doença, o distanciamento social tem sido uma das medidas de contenção mais recomendadas pela ciência, revelando-se, com base em evidências científicas e na experiência de vários países que conseguiram controlar a propagação do vírus, a melhor alternativa para superação do surto e achatamento da curva de contaminação.

Por conta disso, diversas orientações e restrições foram impostas pelo poder público, sob a justificativa de se evitar o contato social. Entre elas, e em total desconexão com as leis vigentes e as recomendações de autoridades médicas, está a restrição do direito ao acompanhante à gestante durante no trabalho de parto, parto e pós-parto, no período da pandemia da Covid-19.

Na Bahia, a Secretaria Estadual de Saúde emitiu a "NOTA TÉCNICA COE SAÚDE No 69 DE 02 DE JUNHO DE 2020: ORIENTAÇÕES ÀS UNIDADES DE SAÚDE DE ASSISTÊNCIA ÀS GESTANTES, PUÉRPERAS E CRIANÇAS MENORES DE 2 ANOS NO CONTEXTO DA PANDEMIA DA Covid-19", dispondo de recomendações às unidades de saúde e secretarias municipais de saúde do estado em relação às formas de restrição à disseminação do SARS-CoV-2 e de proteção à saúde das gestantes, puérperas e crianças menores de 2 anos, em especial quanto à presença e permanência de acompanhantes e visitantes nas unidades de saúde durante a vigência da pandemia, como medida de controle do processo epidêmico da Covid-19 no estado.

Como o recorte do presente estudo é o direito de a gestante ter acompanhante durante o trabalho de parto, parto e pós-parto, destacaremos esse aspecto da referida Norma Técnica. Nessa senda, observamos que o dito documento recomenda que a regra seja a proibição de acompanhante, eis: 


\begin{abstract}
"A presença do acompanhante deve ser restrita às gestantes menores de 16 anos incompletos ou com deficiências ou patologias que dificultem o seu deslocamento ou entendimento das orientações. Este acompanhante deverá ser apenas um (01) durante todo o período de internamento, lembrando que este deverá estar saudável, sem sinais de síndrome gripal e fora do grupo de risco para complicações na eventualidade de uma infecção pelo SARS-CoV-2". (grifos do original).
\end{abstract}

Barbosa e Silva destacam que "as distopias da sociedade brasileira tendem a ser agravadas diante da pandemia. Os que foram alçados à condição de vulnerabilidade social e negação de direitos básicos estarão mais vulneráveis às agruras decorrentes da pandemia" (BARBOSA e SILVA, 2020. p.14). Nesse sentido, a citada Nota Técnica restringe direitos das mulheres, enquanto minoria subalternizada em uma sociedade patriarcal, como a brasileira, e, mais especificamente, das mulheres usuárias do Sistema Único de Saúde (SUS), portanto, em vulnerabilidade social. A pesquisa "Nascer no Brasil, Inquérito Nacional sobre o Parto e Nascimento" (2014) sinalizou que a violência obstétrica se torna mais acentuada para mulheres em situações socioeconômicas de exclusão.

A suspensão generalizada do direito a acompanhante, nos termos recomendados pelo governo baiano, é ilegal e acentua a vulnerabilidade de gênero, à medida que direitos femininos são cerceados e, também, sob o viés de classe, já que tem por alvo mulheres que não podem arcar com o parto na rede privada. Para estas, o direito ao acompanhante durante o trabalho de parto, parto e pós-parto, no período da pandemia da Covid-19 resta garantido como deveria ser para todas.

Segundo consta, a Nota Técnica foi emitida levando em consideração os seguintes dispositivos: a Lei Federal no 13.979, de 6 de fevereiro de 2020, a Portaria n n $^{\circ}$ 188/GM/MS, de 4 de fevereiro de 2020, o Decreto $\mathrm{n}^{\circ} 19.529$ de 16 de março de 2020, e a Lei ${ }^{\circ}$ 11.108, de 07 de abril de 2005. Trata-se, em verdade, de um sofisma, à medida que o cotejo com as normas citadas leva à conclusão diversa da esposada pela Nota Técnica. Senão, vejamos.

A Lei Federal n ${ }^{\circ}$ 13.979, de 6 de fevereiro de 2020, dispõe sobre as medidas a serem adotadas para o enfrentamento da emergência de saúde pública de importância internacional decorrente do novo Coronavírus (SARS-CoV-2). Essa lei arrola as possíveis medidas a serem adotadas diante da pandemia e não faz qualquer menção à restrição de acompanhantes relacionadas ao parto. Relevante destacar que o $\$ 1^{\circ}$, do art. $3^{\circ}$, da Lei $\mathrm{n}^{\circ} 13.979 / 2020$, indica que as medidas previstas em face da pandemia somente poderão ser determinadas com base em evidências científicas e em análises sobre as informações estratégicas em saúde, devendo, quando adotadas, atenderem ao pleno respeito à dignidade, aos direitos humanos e às liberdades fundamentais das pessoas, se atendo ao que dispõe o Regulamento Sanitário Internacional. O direito a acompanhante é corolário dos direitos reprodutivos e, portanto, integra o patrimônio jurídico da gestante como direito humano, assim, de acordo com a Lei $\mathrm{n}^{\mathrm{o}}$ 13.979/2020 deve ser plenamente respeitado. Em suma, não há amparo nessa lei para a suspensão de forma generalizada do direito a acompanhante como esposada na Nota Técnica do governo do estado da Bahia. 
A Portaria n ${ }^{\circ}$ 188/GM/MS, de 4 de fevereiro de 2020, que declara Emergência em Saúde Pública de Importância Nacional (ESPIN), em decorrência da Infecção Humana pelo novo Coronavírus (SARSCoV-2), leva em conta a necessidade de se estabelecer um plano de resposta a esse evento, e da elaboração de uma estratégia de acompanhamento aos nacionais e estrangeiros que ingressarem no país e que se enquadrarem nas definições de suspeitos e confirmados para Infecção Humana pelo novo Coronavírus (2019-nCoV), considerando que a situação demanda o emprego urgente de medidas de prevenção, controle e contenção de riscos, danos e agravos à saúde pública. A portaria em comento considera, entretanto, que a adoção de medidas deverá ser proporcional e restrita aos riscos e também não faz qualquer menção ao direito a acompanhante durante o trabalho de parto, parto e pós-parto.

Já o Decreto no 19.529, de 16 de março de 2020, que regulamenta, no Estado da Bahia, as medidas temporárias para enfrentamento da emergência de saúde pública de importância internacional decorrente do novo Coronavírus, de igual modo, não faz qualquer menção à restrição de acompanhantes durante o parto, ou mesmo, sobre restringir acesso aos hospitais. Muito embora haja previsão, conforme o artigo 16 , de os casos omissos serem decididos pelo Comitê Estadual de Emergência em Saúde Pública (COES/BA), determina em seu artigo $3^{\circ}$, parágrafo terceiro:

$\sqrt{ } 3^{\circ}$ - A adoção das medidas para viabilizar o tratamento ou obstar a contaminação ou a propagação do Coronavírus deverá guardar proporcionalidade com a extensão da situação de emergência.

Pois bem, à luz de uma interpretação fundamentada na dignidade da pessoa humana, não é possível compreender ser razoável ou proporcional que se determine, sem qualquer respaldo científico, a proibição para gestantes, usuárias do SUS, de ter a presença de acompanhante da sua escolha.

A Lei $n^{\circ} 11.108 / 2005$, ao tratar do acompanhante, criou um direito para a gestante e uma obrigação para os serviços de saúde SUS, da rede própria ou conveniada. O art. 19-J assim afirma: "Os serviços de saúde do Sistema Único de Saúde do SUS, da rede própria ou conveniada, ficam obrigados a permitir a presença, junto à parturiente, de 1 (um) acompanhante durante todo o período de trabalho de parto, parto e pós-parto". De acordo com o consolidado magistério de Carlos Maximiliano: "É princípio basilar de hermenêutica jurídica aquele segundo o qual a lei não contém palavras inúteis: verba cum effectu sunt accipienda. Ou seja, as palavras devem ser compreendidas como tendo alguma eficácia. Não se presumem, na lei, palavras inúteis". (MAXIMILIANO, Bastos, 1995, p. 262).

Observa-se, ainda, que no $₫ 2^{\circ}$ do art. 19-J, a referida Lei $n^{\circ} 11.108 / 2005$ estabelece que as ações destinadas a viabilizar o pleno exercício dos direitos tratados por ela serão elaboradas pelo órgão competente do Poder Executivo. Não há, portanto, abertura legislativa para que o Executivo adote medidas arbitrárias que inviabilizam a materialização desse direito sem embasamento científico e amparo legal, uma vez que o papel do referido Poder é garantir a efetivação do direito da gestante de ter acompanhante conforme preceitua a Lei. 
O aparato normativo citado como lastro da Nota Técnica da Secretaria de Saúde do Estado da Bahia não sustenta as premissas de recomendações nela contidas para vedar o direito a acompanhante durante todo o período de trabalho de parto, parto e pós-parto, ao longo da pandemia, e afastar a obrigação da rede de saúde pública e conveniada ao SUS de permitir o acompanhante. Interessante notar que o sofisma da recomendação do governo do estado da Bahia não é pautado apenas pela ausência de suporte da legislação apontada como lastro, mas também no falso discurso da proteção. Assim, a Nota Técnica ceifa o direito/obrigação legal ao acompanhamento sob a justificativa de "que esta medida deve ser também reconhecida como uma ação de humanização da assistência". Como essa medida humaniza se ela retira um direito/obrigação que constitui um dos pilares da humanização, o direito a acompanhante?

Para a manutenção do direito/obrigação do acompanhante em período de pandemia, o Ministério da Saúde, por meio da nota técnica no 9/2020-COSMU/CGCIVI/DAPES/SAPS/MS, determina que:

2.3.2. Mulheres positivas para o vírus SARS-CoV-2 ou suspeitas: o acompanhante permitido deverá ser de convívio diário da paciente, considerando que a permanência junto à parturiente não aumentará suas chances de contaminação; assim sendo, se o acompanhante não for de convívio próximo da paciente nos dias anteriores ao parto, este não deve ser permitido.

2.3.3. Em qualquer situação, não deve haver revezamentos (para minimizar a circulação de pessoas no hospital) e os acompanhantes deverão ficar restritos ao local de assistência à parturiente, sem circulação nas demais dependências do hospital.

2.3.4. O surgimento de sintomas pelo acompanhante em qualquer momento do trabalho de parto e parto implicará no seu afastamento com orientação a buscar atendimento em local adequado.

A ONU Mulheres e a Organização Mundial da Saúde também emitiram recomendação para a manutenção do direito/obrigação ao acompanhante ainda em tempos de pandemia. No Brasil, o Judiciário vem decidindo pela ilegalidade da suspensão desse direito. O Tribunal de Justiça do Mato Grosso do Sul manteve liminar que garantia a manutenção do direito a acompanhante de uma gestante no período de pandemia. O desembargador Alexandre Bastos destacou em seu voto que não existem normas que impeçam tal direito, citando ainda as normativas do parto humanizado. No mesmo sentido, decidiram a Vara da Fazenda Pública de Mogi das Cruzes/SP e a Vara da Fazenda Pública de Paranaguá/PR.

A Defensoria Pública do Estado do Paraná, por meio do Núcleo de Promoção e Defesa dos Direitos da Mulher (NUDEM), em conjunto com a Defensoria Regional dos Direitos Humanos (DRDH) da Defensoria Pública da União, emitiu Recomendação a maternidades de Curitiba a respeito do direito da gestante a um acompanhante antes, durante e após o parto. A Defensoria Pública do Estado do Piauí, por meio de seu Núcleo Especializado da Saúde, obteve liminar favorável para que as gestantes e parturientes tenham direito a acompanhante de sua confiança durante o trabalho de parto, parto e pós-parto nas maternidades públicas da capital e interior do Estado. Já a Defensoria Pública de São Paulo obteve uma decisão judicial liminar para as gestantes que forem dar à luz na Santa Casa de Misericórdia de Mogi das 
Cruzes. A Defensoria de Mato Grosso do Sul também obteve liminar favorável no Tribunal de Justiça em ação civil pública que garantiu às gestantes um acompanhante no momento do parto na Maternidade Cândido Mariano.

$\mathrm{Na}$ constituição do campo de pesquisa, observamos que ações individuais e ações coletivas conseguiram tutela favorável do Poder Judiciário. No que diz respeito às ações coletivas, as defensorias públicas dos estados constituem um importante interlocutor na garantia do direito ao acompanhante, seja no manejo de estratégias judiciais, seja extrajudiciais.

Dessa forma, a manutenção do direito ao acompanhante encontra lastro em recomendações da OMS, do Ministério da Saúde e também abertura para o amparo, por meio de ação individual ou coletiva no Poder Judiciário.

\section{Considerações finais}

Compreende-se que o direito a acompanhante no momento do parto é um direito sexual e reprodutivo da mulher parturiente ou da que sofreu aborto e, como tal, o estado deve envidar esforços para a sua total garantia. Dessa feita, não havendo justificativa plausível para restrição à presença de acompanhante, não é possível suprimir tal direito como medida genérica de combate à disseminação do novo coronavírus, diante da ausência de estudos concretos que recomendem medida tão gravosa que atinge direitos humanos das mulheres.

Cabe ao Estado, em concurso com as usuárias e usuários do SUS, envidar esforços para que o direito à presença de acompanhante seja efetivado ainda em período de pandemia. Segundo essa ótica, o poder público deve garantir os meios capazes de garantir proteção preventiva no ambiente hospitalar, por meio do uso de Equipamentos de Proteção Individual (EPIs) eficientes, para compatibilizar o direito de acompanhante com a saúde das mulheres, crianças e dos profissionais de saúde. Já as usuárias e usuários devem seguir todas as normativas de segurança indicadas pelas autoridades de saúde.

Santos (2020) afirma que a quarentena será particularmente difícil para as mulheres e que o machismo que impera se reforça em momentos de crise. É notório que a negativa do direito ao acompanhante tem um componente de gênero à medida que as mulheres são atingidas pela retirada ilegítima de uma garantia legal. No Brasil, ainda impera em diversas frentes a violação de direitos femininos, seja pelos altos índices de violência doméstica e intrafamiliar agravados durante a pandemia, seja pelas desigualdades nas relações laborativas. Em uma sociedade patriarcal, qualquer ato que atinja direitos das mulheres afronta a cidadania feminina. 
Ademais, negar o direito a acompanhante de forma generalizada, como fez a Nota Técnica baiana, fere não apenas a lei, mas nega a luta dos movimentos feministas na formalização desses direitos pela via legislativa e solapa luta histórica de conquista da cidadania feminina. Negar o direito ao acompanhante de forma generalizada é institucionalizar a violência obstétrica e referendar uma espécie de violência contra a mulher.

Do ponto de vista de classe, essa negativa, recomendada pela Nota Técnica do Estado da Bahia, acentua desigualdades porque a mulher que pode parir na rede privada tem o direito a acompanhante garantido enquanto, para a usuária do SUS, tal garantia é negada pelo Estado, justamente aquele que deveria zelar pela efetivação desse direito.

Logo, conclui-se que, previsto na legislação regulamentadora do Sistema Único de Saúde (SUS), em concordância com a Lei $\mathrm{n}^{\circ}$ 11.108/2005, marco brasileiro na busca pelo respeito aos direitos sexuais e reprodutivos das mulheres, o direito a acompanhante da mulher parturiente ou em processo abortivo deve ser preservado pelas instituições de saúde públicas ou conveniadas, sob pena de incorrer na violação de direitos humanos, uma vez que o "remédio" não deve ser pior que o mal o qual busca combater.

\section{Referências}

BARBOSA, Fábio Ramos e SILVA, Luciana Santos. A Crise Dentro da Crise: a Covid-19 e a Emenda Constitucional 95 inCovid-19 e Direito Brasileiro. Mudanças e Impactos. São Paulo: Tirantlo Blanc, 2020.

BANDEIRA, Lourdes Maria. Violência de gênero: a construção de um campo teórico e de investigação.Revista Sociedade e Estado, v. 29; n. 2; Brasilia, maio/agosto, 2014.

DODOU, Hilana Dayana et al . A contribuição do acompanhante para a humanização do parto e nascimento: percepções de puérperas. Esc. Anna Nery Revista de Enfermagem, Rio de Janeiro, v. 18, n. 2, p. 262-269, Junho de 2014. Disponível em < https://www.scielo.br/pdf/ean /v18n2/1414-8145ean-18-02-0262.pdf > Acesso em 09 abr. 2020.

LONGO, Cristiane Silva Mendonça; ANDRAUS, Lourdes Maria Silva; BARBOSA, Maria Alves. Participação do acompanhante na humanização do parto e sua relação com a equipe de saúde. Revista Eletrônica de Enfermagem, v. 12, n. 2, p. 386-391, 5 jul. 2010.

MAXIMILIANO, Carlos.Hermenêutica e Aplicação do Direito. 8a. ed., Freitas Bastos, 1995, p. 262.

Nascer no Brasil, Inquérito Nacional sobre o Parto e Nascimento, Coordenação Maria do Carmo Leal, Cadernos de Saúde Pública, volume 30, 2014.

RAMOS, André de Carvalho. Curso de Direitos Humanos.7. ed. - São Paulo: Saraiva Educação 2020.

SAFFIOTI, Heleieth. Gênero, patriarcado, violência. São Paulo: Editora Fundação Perseu Abramo, 2007.

SANTOS, Boaventura de Sousa. Para uma revolução democrática da justiça. São Paulo: Cortez, 2011. 
A cruel pedagogia do vírus. Coimbra: Edições Almedina, S.A, 2020.

Recebido em: junho de 2020. Aprovado em: julbo de 2020. 